\title{
Intraoperative management of critical arrhythmia
}

\author{
Chang Hee Kwon ${ }^{1}$ and Seong-Hyop Kim ${ }^{2}$ \\ ${ }^{1}$ Division of Cardiology, Department of Internal Medicine, ${ }^{2}$ Department of Anesthesiology and Pain Medicine, \\ Konkuk University Medical Center, Konkuk University School of Medicine, Seoul, Korea
}

The incidence of intraoperative arrhythmia is extremely high, and some arrhythmias require clinical attention. Therefore, it is essential for the anesthesiologist to evaluate risk factors for arrhythmia and understand their etiology, electrophysiology, diagnosis, and treatment. Anesthetic agents reportedly affect normal cardiac electrical activity. In the normal cardiac cycle, the sinoatrial node initiates cardiac electrical activity through intrinsic autonomous pacemaker activity. Sequential atrial and ventricular contractions result in an effective cardiac pumping mechanism. Arrhythmia occurs due to various causes, and the cardiac pumping mechanism may be affected. A severe case may result in hemodynamic instability. In this situation, the anesthesiologist should eliminate the possible causes of arrhythmia and manage the condition, creating hemodynamic stability under proper electrocardiographic monitoring.

Key Words: Anesthesia, Cardiac arrhythmias, Cardiac cycle.

\section{Introduction}

Arrhythmia is one of the most common cardiovascular complications during anesthesia. Its occurrence has been reported in $70 \%$ of patients undergoing general anesthesia for various surgical procedures [1,2]. Patients undergoing cardiac surgeries are more vulnerable to arrhythmia. Intraoperative arrhythmia is clinically important because it can be associated with significant hemodynamic instability. In this manuscript, we explain the mechanism, diagnosis, and treatment of intraoperative critical arrhythmias other than ischemia-related arrhythmia.

Corresponding author: Seong-Hyop Kim, M.D., Ph.D.

Department of Anesthesiology and Pain Medicine, Konkuk University Medical Center, Konkuk University School of Medicine, 120-1, Neungdong-ro, Gwangjin-gu, Seoul 05030, Korea

Tel: 82-2-2030-5454, Fax: 82-2-2030-5449

Email: yshkim75@naver.com

ORCID: http://orcid.org/0000-0001-7764-9818

Received: January 26, 2017.

Revised: January 30, 2017.

Accepted: January 31, 2017.

Korean J Anesthesiol 2017 April 70(2): 120-126

https://doi.org/10.4097/kjae.2017.70.2.120

\section{Normal Sinus Rhythm and Anti-arrhythmic Agents}

To understand arrhythmia, the definition of normal sinus rhythm should be understood. Normal cardiac electrical conduction occurs as follows: the cardiac impulse begins in the sinoatrial (SA) node and travels to both atria; the atria depolarize and generate the $\mathrm{P}$ wave; the impulse travels to the atrioventricular (AV) node, where the speed is reduced; the impulse through the AV node travels down the His bundle and Purkinje fibers; and finally, the impulse of the Purkinje fibers rapidly distributes and depolarizes the ventricles and generates the QRS wave. Therefore, the normal sinus rhythm is conventionally defined as the result of normal cardiac electrical conduction with normal shapes of waves, normal duration of intervals, and a rate between 60 and 100 beats/min for adults.

Normal cardiac electrical conduction starts from the cardiac action potential, and is generated by the movements of ions through ion channels in the cardiac cells. The action potential of the myocardium is composed of five phases, and the activation of ion channels at each phase is distinct (Fig. 1). The mechanism of arrhythmia is roughly divided into three categories [3]: 1) increased automaticity due to reduced threshold of the action potential or increased slope of phase 4 depolarization; 2) triggered

(c) This is an open-access article distributed under the terms of the Creative Commons Attribution Non-Commercial License (http://creativecommons.org/ licenses/by-nc/4.0/), which permits unrestricted non-commercial use, distribution, and reproduction in any medium, provided the original work is properly cited. 
activity due to afterdepolarization reaching the threshold of the action potential; and 3) circus movement or re-entry. Arrhythmia does not need instant treatment if it is not accompanied by hemodynamic instability. Arrhythmia can make the heart pump ineffectively, and can produce blood clots. Therefore, the goals of treatment are prevention of blood clots to reduce the risk of stroke, control of the heart rate (HR) within a relatively normal range, restoration of normal $\mathrm{HR}$ if possible, correction of the condition that caused the arrhythmia, and reduction of other risk factors for heart disease and stroke. If arrhythmia occurs, the problem exists in the process of the cardiac action potential with electrical conduction. Therefore, the agents for control of cardiac action potential with electrical conduction are anti-ar-
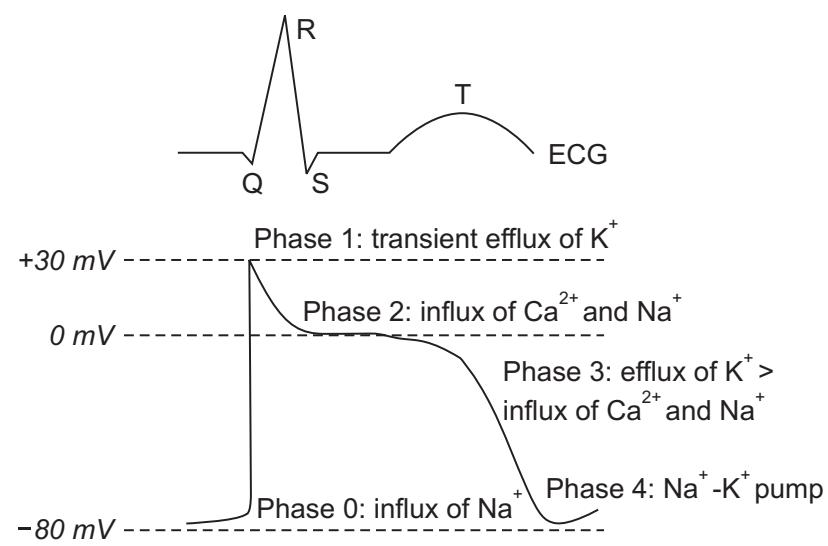

Fig. 1. Electrocardiograph (ECG) and cardiac action potential of the ventricle. rhythmic agents. The type of anti-arrhythmic agent is classified based on the action site of the ion channel (Table 1).

\section{Causes of Intraoperative Arrhythmia}

The causes of intraoperative arrhythmia can be divided into three groups: patient, surgical procedure, and anesthesia. Patients with cardiac disease have a much higher incidence of intraoperative arrhythmia than those without. Patients with intracranial disease may show electrocardiographic (ECG) abnormalities. Postoperative atrial fibrillation occurs more often in elderly patients compared to younger patients. Cardiac surgery, including direct surgical manipulation and procedures related to cardiopulmonary bypass, may precipitate arrhythmia. Dental surgery is often associated with arrhythmias due to profound frequent stimulation of the autonomous nervous system. Severe bradycardia due to the oculocardiac reflex during strabismus surgery commonly occurs, particularly in neonates and children. Direct or indirect stimulation of vagal tone in surgical procedures produces bradycardia or block. Various factors associated with anesthesia influence the occurrence of arrhythmia. Anesthetic agents themselves are arrhythmogenic. Evaluation of the influence of anesthetic agents on ventricular repolarization is important because the agents may cause malignant ventricular arrhythmias, such as torsade de pointes [4]. This topic is detailed in the next chapter. Abnormal blood gas or electrolytes, autonomic nervous stimulation, central venous cannulation, and so on can result in arrhythmia. The most common cause of intraoperative arrhythmia is endotracheal intubation, which ac-

Table 1. Anti-arrhythmic Agents

\begin{tabular}{|c|c|c|c|c|}
\hline Class & Basic mechanism & Comments & Drugs & Uses \\
\hline I & $\begin{array}{l}\text { Sodium-channel } \\
\text { blockade }\end{array}$ & $\begin{array}{l}\text { Reduce phase } 0 \text { slope and peak of action } \\
\text { potential }\end{array}$ & & \\
\hline IA & Moderate & $\begin{array}{l}\text { Moderate reduction in phase } 0 \text { slope; increase } \\
\text { action potential duration; increase effective } \\
\text { refractory period. }\end{array}$ & $\begin{array}{l}\text { Quinidine, procainamide, } \\
\text { disopyramide }\end{array}$ & $\begin{array}{l}\text { Ventricular arrhythmias, } \\
\text { atrial fibrillation }\end{array}$ \\
\hline IB & Weak & $\begin{array}{l}\text { Small reduction in phase } 0 \text { slope; reduce } \\
\text { action potential duration; decrease effective } \\
\text { refractory period. }\end{array}$ & Lidocaine, tocainide, mexiletine & Ventricular arrhythmias \\
\hline IC & Strong & $\begin{array}{l}\text { Pronounced reduction in phase } 0 \text { slope; } \\
\text { no effect on action potential duration or } \\
\text { effective refractory period. }\end{array}$ & Flecainide, propafenone & $\begin{array}{l}\text { Paroxysmal atrial } \\
\text { fibrillation }\end{array}$ \\
\hline II & Beta-blockade & $\begin{array}{l}\text { Block sympathetic activity; reduce rate and } \\
\text { conduction }\end{array}$ & $\begin{array}{l}\text { Acebutolol, atenolol, bisoprolol, } \\
\text { esmolol, metoprolol, nadolol, } \\
\text { propranolol, carvedilol, labetalol }\end{array}$ & \\
\hline III & $\begin{array}{l}\text { Potassium-channel } \\
\text { blockade }\end{array}$ & $\begin{array}{l}\text { Delay repolarization (phase } 3 \text { ) and thereby } \\
\text { increase action potential duration and } \\
\text { effective refractory period }\end{array}$ & $\begin{array}{l}\text { Sotalol, dofetilide, ibutilide, } \\
\text { bretylium, amidodarone }\end{array}$ & $\begin{array}{l}\text { Ventricular arrhythmias, } \\
\text { atrial fibrillation }\end{array}$ \\
\hline IV & $\begin{array}{l}\text { Calcium-channel } \\
\text { blockade }\end{array}$ & $\begin{array}{l}\text { Block L-type calcium-channels; most effective } \\
\text { at sinoatrial and atrioventricular nodes; } \\
\text { reduce rate and conduction }\end{array}$ & $\begin{array}{l}\text { Amlodipine, felodipine, } \\
\text { isradipine, nicardipine, nifedine, } \\
\text { diltiazem, verapamil }\end{array}$ & \\
\hline
\end{tabular}


companies hemodynamic disturbance by autonomic reflexes.

\section{Anesthetic Agents and Arrhythmia}

Drug-induced prolonged ventricular repolarization is associated with torsade de pointes and sudden cardiac arrest [4]. Torsade de pointes is characterized by polymorphic QRS complexes twisting around the isoelectric line, and is typically related to QT interval prolongation and the R-on-T phenomenon [5]. ECG markers for QT interval [6], QT interval corrected with HR (QTc) [7-10], JT interval [11], QT dispersion (QTd) [12], QT variability index [13], and transmural dispersion of repolarization (TDR) are used to check for the possibility of torsade de pointes [14,15]. All of the inhaled anesthetic agents prolong QTc and QTd, whereas sevoflurane does not affect TDR [4]. Propofol does not significantly affect QTc, regardless of cardiovascular disease [16-18]. Opioids have no effects on QTc [4], but a high dose of sufentanil may produce QT interval prolongation $[19,20]$. Succinylcholine significantly prolongs the QT interval and QTc, particularly with thiopental $[21,22]$, although most non-depolarizing neuromuscular blockers have not been associated with prolongation [23]. However, the combination of anticholinesterase and anticholinergics to reverse neuromuscular blockade causes transient but significant prolongation of QTc $[24,25]$. On the other hand, sugammadex is relatively safe $[26,27]$. Local anesthetic agents have no significant effects on QTc [28,29]; however, the level of blockade can influence ECG $[30,31]$. Interscalene brachial plexus block with ropivacaine or bupivacaine do not produce any change in QT interval or QTc [32]. Adjuvant agents related to anesthesia may be a cause for concern. The Food and Drug Administration issued a black box warning on droperidol, an anti-emetic agent, for sudden potential cardiac death [33]. Serotonin type 3 receptor antagonists, potent anti-emetic agents, are also associated with prolongation of QTc [34,35]. Consensus guidelines for the management of postoperative nausea and vomiting suggest that care should be taken when using those anti-emetic agents in patients with prolonged QT interval [36].

\section{Identification of Intraoperative Arrhythmia and Management}

The types of arrhythmia are classified by such factors as HR, mechanism, duration, and origin. For the identification of intraoperative arrhythmia and its management, the anesthesiologist should be aware of the following: 1) What is HR? 2) Is the rhythm regular or irregular? 3) Is one P present for each QRS? 4) Is the QRS normal? 5) Is the rhythm associated with hemodynamic instability? 6) Does the rhythm require treatment?

\section{Sinus bradycardia and sinus tachycardia}

Conventionally, sinus bradycardia is defined as $\mathrm{HR}<60$ beats/min, and sinus tachycardia is defined as HR $>100$ beats/ min at resting state in adults. Generally, maximal HR is considered to be $(220$ - age) beats/min. Both arrhythmias have a regular rhythm, a ratio of $\mathrm{P}$ to QRS of $1: 1$, and a normal QRS, although severe sinus tachycardia is accompanied by ST depression. Because marked sinus bradycardia with $\mathrm{HR}<40$ beats/min may be poorly tolerated in healthy patients, the causes should be identified before treatment of the arrhythmia for maintenance of cardiac output. The treatments of sinus bradycardia are all attempts to increase $\mathrm{HR}$, including pacing. If the patient is stable, despite marked sinus bradycardia, close observation may suffice. However, in cases with signs of inadequate systemic perfusion, such as hypotension or electrocardiographic evidence of ischemia, pharmacologic therapy or temporary percutaneous pacing may be necessary. Intravenous atropine of $0.5 \mathrm{mg}$ is used as firstline therapy for the treatment of bradycardia, and may need to be repeated every 3 to $5 \mathrm{~min}$ up to a total of $3 \mathrm{mg}$. If bradycardia persists despite intravenous atropine, positive chronotropic agents such as isoproterenol, dopamine, dobutamine, and epinephrine may be needed to increase HR. In some cases, bradycardia degenerates into asystole, and thus, immediate cardiopulmonary resuscitation is necessary. This serious circumstance can be induced by vagal reflex with venipuncture or epidural puncture. The most common cause of sinus bradycardia is autonomic disturbance including vasovagal stimulation. Hypoxia, hypothermia, endotracheal suctioning, and increased intracranial pressure are also associated with sinus bradycardia. Conversely, the causes of sinus tachycardia include pain, fever, and hypercarbia. Sinus tachycardia is the most common arrhythmia occurring in the perioperative period. The most common cause of sinus tachycardia is hypovolemia or inadequate anesthetic depth, and the correction of these conditions is the first step in the treatment of sinus tachyarrhythmia. The treatments of sinus tachycardia are all attempts to decrease HR.

\section{AV block}

Intraoperative AV block may occur in the settings of intrinsic cardiac disease, perioperative ischemia, electrolyte abnormalities, excessive vagal tone, or iatrogenic causes including surgical aortic valve replacement. Most cases of intraoperative AV block are transient and do not require pacing. However, this arrhythmia may be persistent or permanent, and thus, an epicardial pacing system is necessary when AV block develops in cardiac surgery, particularly in aortic or mitral valve surgery. AV block is classified as first, second, and third (complete) degree. Firstdegree AV block does not require treatment. In second-degree 
AV block, pacing may be required if bradycardia is severe or causes hemodynamic instability. Third-degree AV block is characterized by $\mathrm{P}$ waves that are discordant with QRS waves. Pacing is usually required because escape junctional or ventricular rhythm is usually very slow at $<40$ beats/min. This information is shown in Fig. 2.

\section{Paroxysmal supraventricular tachycardia (PSVT)}

PSVT has a regular rhythm, and a ratio of $\mathrm{P}$ to QRS of $1: 1$ with normal QRS at HRs of 130-270 beats/min. It also shows an ischemic change in ECG such as sinus tachycardia. The $\mathrm{P}$ wave may often be hidden in the QRS complex or T wave. The mechanism of PSVT is different from that of sinus tachycardia. PSVT occurs as the result of excessive stimulation of the SA node; atrial excitation outside of the SA node; AV nodal reentry; and re-entry through a bypass tract. To rule out or differentiate PSVT from sinus tachycardia or atrial flutter/fibrillation, carotid sinus massage or intravenous injection of edrophonium $5-10 \mathrm{mg}$ is applied. Recently, intravenous adenosine (6 mg) was shown to rapidly slow AV nodal function, and has been easily used to differentiate or treat PSVT. Theoretically, AV nodal reentrant tachycardia and AV re-entrant tachycardia are terminated by intravenous adenosine. Up to $80 \%$ of atrial tachycardias may be terminated by adenosine. However, atrial flutter or atrial fibrillation was not terminated by adenosine. If the response to adenosine fails, a double dose of adenosine should be tested. For treatment, adenosine is the drug of choice. Other agents that decrease HR or cardioversion are used for the treatment of PSVT. If PSVT persists with focal atrial impulses or atrioventricular re-entry electrical ablation with radiofrequency energy can be performed. This information is shown in Fig. 2.

\section{Atrial flutter and fibrillation}

Atrial flutter has a regular rhythm, regular rhythm, and a P and QRS ratio of 2:1 or 3:1, with normal QRS at HRs of 250-300 atrial beats/min with 150 ventricular beats/min. The mechanism of atrial flutter is macro re-entrant arrhythmia, circulating in a specific manner in the right atrium. Atrial flutter with very fast $\mathrm{HR}$ is usually accompanied by AV block, manifesting 2 : 1-4 : $1 \mathrm{AV}$ conduction. Classic saw-tooth waves, socalled $\mathrm{F}$ waves, are usually present. $\mathrm{T}$ waves are lost in $\mathrm{F}$ waves. The treatment of atrial flutter should be started after consideration of the existence of thromboembolism. Pharmacologic or synchronized cardioversion is used for treatment of atrial flutter. Atrial fibrillation has an irregularly irregular rhythm, and normal QRS at HRs of 350-500 atrial beats/min and 60-170 ventricular beats/min. The $\mathrm{P}$ wave is absent and is replaced by $\mathrm{F}$ waves. The mechanism of atrial fibrillation has been suggested to involve multiple electrical wavelets caused by abnormal foci, micro or macro re-entrant, and so on. Atrial fibrillation causes an excessively rapid and irregular atrial contraction with no obvious atrial kick. It is called irregularly irregular and may be associated with a pulse deficit. The significance of atrial fibrillation is that the loss of atrial kick is associated with reduction of left ventricular filling and stroke volume. Consequently, hemodynamic instability occurs. The loss of obvious atrial kick can produce atrial thrombi, resulting in pulmonary and systemic thromboembolism. The treatment of atrial fibrillation is similar to the treatment of atrial flutter. It should be noted that, if atrial fibrillation is present for longer than $48 \mathrm{~h}$, attempts to restore
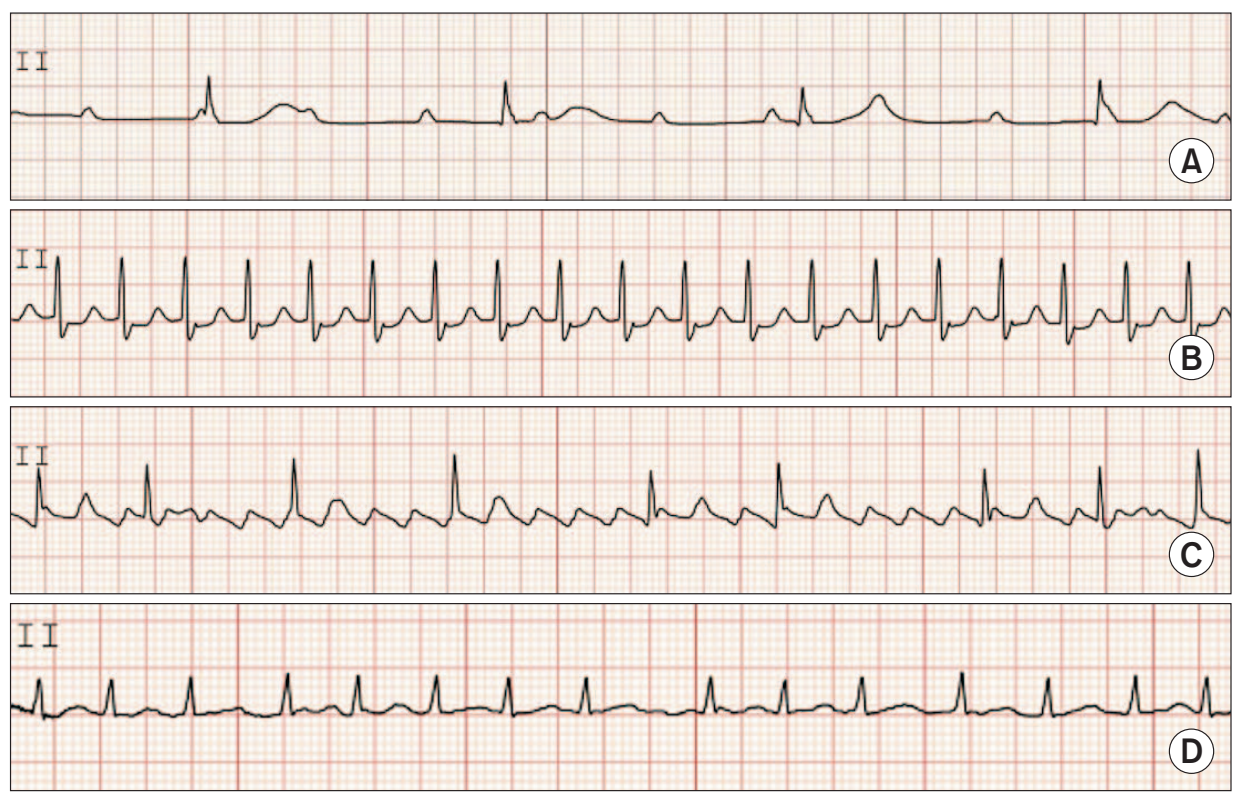

Fig. 2. Atrioventricular block (A), paroxysmal supraventricular tachycardia (B), atrial flutter (C), atrial fibrillation (D). 
sinus rhythm may increase the risk of thromboembolism. This information is shown in Fig. 2.

\section{Premature ventricular contraction (PVC)}

PVC has an irregular rhythm. It has no associated $\mathrm{P}$ wave because PVC results from ectopic pacemaker activity arising below the AV node. PVC also has a wide ( $>0.12$ second) and bizarre QRS, because it originates in and spreads through the myocardium or ventricular conducting system. PVC is frequently observed during anesthesia. Its clinical significance is limited. However, a new onset of PVC should be considered a potentially serious event as it may lead to ventricular tachycardia/fibrillation. This information is shown in Fig. 3.

\section{Ventricular tachycardia (VT) and ventricular fibrillation (VF)}

If three or more sequential PVCs are present, it is defined as VT. VT shows fusion, capture beats, and atrioventricular dissociation in an ECG. VT has a regular rhythm at HRs of 100-200 beats/min. The ratio of $\mathrm{P}$ and QRS has no fixed relationship because of atrioventricular dissociation. VT is a life-threatening state and needs emergent treatment. Amiodarone is recommended for treatment. Amiodarone is a type III anti-arrhythmic agent, but it also has the properties of I, II, and IV. Intravenous administration of amiodarone $(150 \mathrm{mg}$ ) for longer than $10 \mathrm{~min}$ is used for a loading dose. After the loading dose, $1 \mathrm{mg} / \mathrm{min}$ for $6 \mathrm{~h}$ and $0.5 \mathrm{mg} / \mathrm{min}$ for $18 \mathrm{~h}$ is followed by dose reduction or administration by the oral route. Synchronized cardioversion is applied for hemodynamic instability. VF has an irregular and grossly disorganized HR, totally irregular rhythm, and no relationship between $\mathrm{P}$ and QRS. The QRS is absent. It means that no effective cardiac contraction with output exists. Immediate cardiopulmonary resuscitation is required. A non-synchronized defibrillation with 200-360 J is used. Biphasic shock reduces the required energy level and increases the efficacy of defibrillation. Magnesium sulfate may facilitate defibrillation. Epinephrine can be used to coarsen fibrillation just before defibrillation. It can also facilitate defibrillation. This information is shown in Fig. 3.

\section{Torsade de pointes}

Torsade de pointes is usually invoked in the situation of prolonged QT interval or bradycardia. Therefore, the anesthesiologist should check the baseline QT interval and check for drugs that prolong QT interval before operation because prolongation of QT interval may increase the risk for torsade de pointes. Many anesthetic agents may cause mild prolongation of the QT interval, but are not likely to cause torsade de pointes, although some case reports of intraoperative torsade de pointes under specific anesthetic agents have been published [37,38]. Therefore, anesthesiologists should pay special attention to the changes in QT interval and HR during anesthesia. If the patient
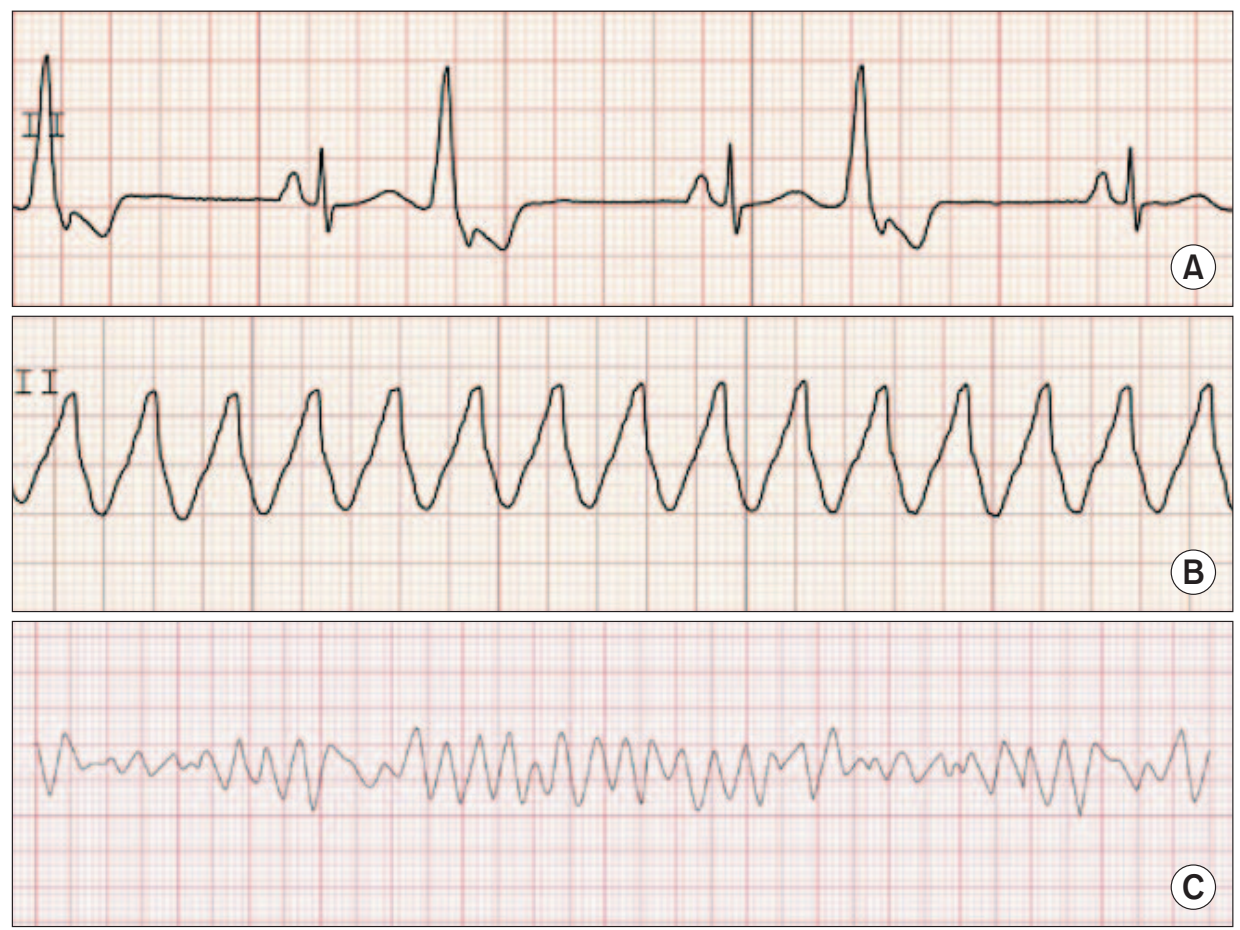

(C)

Fig. 3. Premature ventricular contraction (A), ventricular tachycardia $(B)$, ventricular fibrillation (C). 


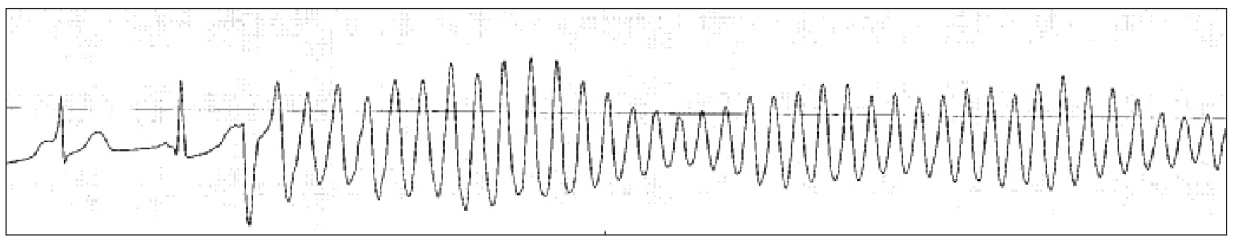

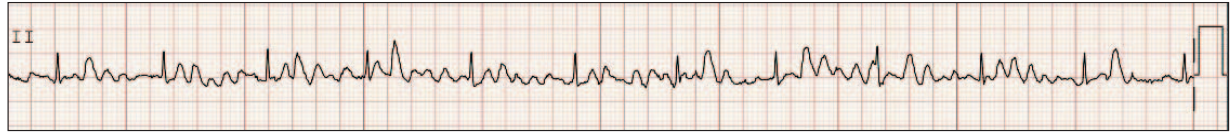

Fig. 4. Torsade de pointes.

Fig. 5. Artifacts. is hemodynamically unstable, defibrillation should be delivered promptly. However, if the patient has recurrent non-sustained episodes of torsade de pointes in the perioperative period, firstline therapy is administration of magnesium sulfate $2 \mathrm{~g}$ as a slow intravenous bolus. This information is shown in Fig. 4.

\section{Artifacts}

In some cases, such as patient movement and electrocautery, artifacts in ECG monitoring can lead anesthesiologists to misinterpret ECGs as indicating atrial fibrillation or VF (Fig. 5). In these situations, the anesthesiologist should check the patient's vital signs, particularly arterial pulse or arterial blood pressure monitoring, and correct the potential causes that can induce artifacts.

\section{Conclusions}

Intraoperative arrhythmia can occur under any circumstances during anesthesia. If it occurs, the anesthesiologist should identify the precipitating factors and manage them, even if the arrhythmia is not associated with hemodynamic instability. The understanding of intraoperative arrhythmia on an electrophysiologic and pharmacologic basis can help anesthesiologists easily manage this condition.

\section{ORCID}

Chang Hee Kwon, http://orcid.org/0000-0001-8716-1146

Seong-Hyop Kim, http://orcid.org/0000-0001-7764-9818

\section{References}

1. Forrest JB, Cahalan MK, Rehder K, Goldsmith CH, Levy WJ, Strunin L, et al. Multicenter study of general anesthesia. II. Results. Anesthesiology 1990; 72: 262-8.

2. Forrest JB, Rehder K, Cahalan MK, Goldsmith CH. Multicenter study of general anesthesia. III. Predictors of severe perioperative adverse outcomes. Anesthesiology 1992; 76: 3-15.

3. Dua N, Kumra VP. Management of perioperative arrhythmias. Indian J Anaesth 2007; 51: 310-23.

4. Staikou C, Stamelos M, Stavroulakis E. Impact of anaesthetic drugs and adjuvants on ECG markers of torsadogenicity. Br J Anaesth 2014; 112: 217-30.

5. Viskin S. Long QT syndromes and torsade de pointes. Lancet 1999; 354: 1625-33.

6. Laguna P, Thakor NV, Caminal P, Jané R, Yoon HR, Bayés de Luna A, et al. New algorithm for QT interval analysis in 24-hour Holter ECG: performance and applications. Med Biol Eng Comput 1990; 28: 67-73.

7. Bazett JC. An analysis of time relation of electrocardiograms. Heart 1920; 7: 353-67.

8. Fridericia LS. The duration of systole in an electrocardiogram in normal humans and in patients with heart disease. Acta Med Scand 1920; 53: 469-86.

9. Sagie A, Larson MG, Goldberg RJ, Bengtson JR, Levy D. An improved method for adjusting the QT interval for heart rate (the Framingham Heart Study). Am J Cardiol 1992; 70: 797-801.

10. Hodges M, Salerno Q, Erlien D. Bazett's QT correction reviewed. Evidence that a linear QT correction for heart rate is better. J Am Coll Cardiol 1983; 1: 694.

11. Crow RS, Hannan PJ, Folsom AR. Prognostic significance of corrected QT and corrected JT interval for incident coronary heart disease in a general population sample stratified by presence or absence of wide QRS complex: the ARIC Study with 13 years of follow-up. Circulation 2003; 108: 1985-9.

12. Higham PD, Campbell RW. QT dispersion. Br Heart J 1994; 71: 508-10. 
13. Berger RD, Kasper EK, Baughman KL, Marban E, Calkins H, Tomaselli GF. Beat-to-beat QT interval variability: novel evidence for repolarization lability in ischemic and nonischemic dilated cardiomyopathy. Circulation 1997; 96: 1557-65.

14. Antzelevitch C. Role of transmural dispersion of repolarization in the genesis of drug-induced torsades de pointes. Heart Rhythm $2005 ; 2$ (2 Suppl): S9-15.

15. Yan GX, Lankipalli RS, Burke JF, Musco S, Kowey PR. Ventricular repolarization components on the electrocardiogram: cellular basis and clinical significance. J Am Coll Cardiol 2003; 42: 401-9.

16. Lischke V, Wilke HJ, Probst S, Behne M, Kessler P. Prolongation of the QT-interval during induction of anesthesia in patients with coronary artery disease. Acta Anaesthesiol Scand 1994; 38: 144-8.

17. Michaloudis DG, Kanakoudis FS, Petrou AM, Konstantinidou AS, Pollard BJ. The effects of midazolam or propofol followed by suxamethonium on the QT interval in humans. Eur J Anaesthesiol 1996; 13: 364-8.

18. Lindgren L, Yli-Hankala A, Randell T, Kirvelä M, Scheinin M, Neuvonen PJ. Haemodynamic and catecholamine responses to induction of anaesthesia and tracheal intubation: comparison between propofol and thiopentone. Br J Anaesth 1993; 70: 306-10.

19. Blair JR, Pruett JK, Crumrine RS, Balser JJ. Prolongation of QT interval in association with the administration of large doses of opiates. Anesthesiology 1987; 67: 442-3.

20. Blair JR, Pruett JK, Introna RP, Adams RJ, Balser JS. Cardiac electrophysiologic effects of fentanyl and sufentanil in canine cardiac Purkinje fibers. Anesthesiology 1989; 71: 565-70.

21. Scheinin B, Scheinin M, Vuorinen J, Lindgren L. Alfentanil obtunds the cardiovascular and sympathoadrenal responses to suxamethoniumfacilitated laryngoscopy and intubation. Br J Anaesth 1989; 62: 385-92.

22. Lindgren L, Rautiainen P, Klemola UM, Saarnivaara L. Haemodynamic responses and prolongation of QT interval of ECG after suxamethonium-facilitated intubation during anaesthetic induction in children: a dose-related attenuation by alfentanil. Acta Anaesthesiol Scand 1991; 35: 355-8.

23. Staikou C, Chondrogiannis K, Mani A. Perioperative management of hereditary arrhythmogenic syndromes. Br J Anaesth 2012; 108: 73044.

24. Schwartz PJ, Bonazzi O, Locati E, Napolitano C, Sala S. Pathogenesis and therapy of the idiopathic long QT syndrome. Ann N Y Acad Sci 1992; 644: 112-41.

25. Saarnivaara L, Simola M. Effects of four anticholinesterase-anticholinergic combinations and tracheal extubation on QTc interval of the ECG, heart rate and arterial pressure. Acta Anaesthesiol Scand 1998; 42: 460-3.

26. Bom A, Bradley M, Cameron K, Clark JK, Van Egmond J, Feilden H, et al. A novel concept of reversing neuromuscular block: chemical encapsulation of rocuronium bromide by a cyclodextrin-based synthetic host. Angew Chem Int Ed Engl 2002; 41: 266-70.

27. Pühringer FK, Rex C, Sielenkämper AW, Claudius C, Larsen PB, Prins ME, et al. Reversal of profound, high-dose rocuronium-induced neuromuscular blockade by sugammadex at two different time points: an international, multicenter, randomized, dose-finding, safety assessor-blinded, phase II trial. Anesthesiology 2008; 109: 188-97.

28. Knudsen K, Beckman Suurküla M, Blomberg S, Sjövall J, Edvardsson N. Central nervous and cardiovascular effects of i.v. infusions of ropivacaine, bupivacaine and placebo in volunteers. Br J Anaesth 1997; 78: 507-14.

29. Stewart J, Kellett N, Castro D. The central nervous system and cardiovascular effects of levobupivacaine and ropivacaine in healthy volunteers. Anesth Analg 2003; 97: 412-6.

30. Owczuk R, Sawicka W, Wujtewicz MA, Kawecka A, Lasek J, Wujtewicz M. Influence of spinal anesthesia on corrected QT interval. Reg Anesth Pain Med 2005; 30: 548-52.

31. Ornek E, Ornek D, Alkent ZP, Ekin A, Basaran M, Dikmen B. The effects of volatile induction and maintenance of anesthesia and selective spinal anesthesia on QT interval, QT dispersion, and arrhythmia incidence. Clinics (Sao Paulo) 2010; 65: 763-7.

32. Borgeat A, Ekatodramis G, Blumenthal S. Interscalene brachial plexus anesthesia with ropivacaine $5 \mathrm{mg} / \mathrm{mL}$ and bupivacaine $5 \mathrm{mg} / \mathrm{mL}$ : effects on electrocardiogram. Reg Anesth Pain Med 2004; 29: 557-63.

33. Gan TJ, White PF, Scuderi PE, Watcha MF, Kovac A. FDA "black box" warning regarding use of droperidol for postoperative nausea and vomiting: is it justified? Anesthesiology 2002; 97: 287.

34. Kim HJ, Lee HC, Jung YS, Lee J, Min JJ, Hong DM, et al. Effect of palonosetron on the QTc interval in patients undergoing sevoflurane anaesthesia. Br J Anaesth 2014; 112: 460-8.

35. Lee JH, Park YH, Kim JT, Kim CS, Kim HS. The effect of sevoflurane and ondansetron on QT interval and transmural dispersion of repolarization in children. Paediatr Anaesth 2014; 24: 421-5.

36. Gan TJ, Diemunsch P, Habib AS, Kovac A, Kranke P, Meyer TA, et al. Consensus guidelines for the management of postoperative nausea and vomiting. Anesth Analg 2014; 118: 85-113.

37. Kumakura M, Hara K, Sata T. Sevoflurane-associated torsade de pointes in a patient with congenital long QT syndrome genotype 2. J Clin Anesth 2016; 33: 81-5.

38. Chung EJ, Jeon YS, Kim HJ, Lee KH, Lee JW, Han KA, et al. Torsade de pointes in liver transplantation recipient after induction of general anesthesia: a case report. Korean J Anesthesiol 2014; 66: 80-4. 